\title{
VIGAS DE CONCRETO REFORÇADO COM FIBRAS DE AÇO SUBMETIDAS À FLEXÃO
}

\author{
Reinforced concrete beams with steel fibers submitted to flexion
}

\author{
Valquiria Claret dos SANTOS ${ }^{1}$, Paulo Cesar GONÇALVES², Adinele Gomes GUIMARÃES ${ }^{3}$, \\ Felipe Ott CABALLER ${ }^{4}$
}

Recebido em 21 de janeiro de 2019; aceito em 28 de setembro de 2019; disponível on-line em 11 de maio de 2020.

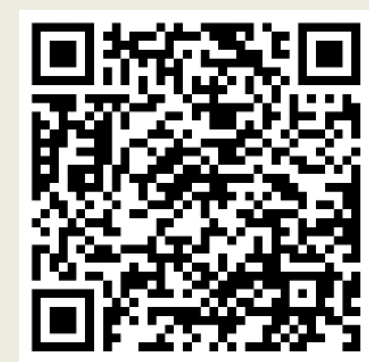

PALAVRAS CHAVE:

Concreto;

Entalhe;

Fibras de Aço;

Ensaio à Flexão.

\section{KEYWORDS:}

Concrete ;

Notch;

Steel Fibers;

Bending Test.

RESUMO: O presente trabalho compara experimentalmente os resultados de ensaios à flexão a quatro pontos de vigas de concreto com e sem adição de fibras de aço. 0 objetivo principal do trabalho foi analisar as influências que as fibras de aço tendem em modificar o surgimento de patologias relacionadas à fissuração do concreto. Este trabalho se justifica pelo fato de que a implementação de elementos de reforço ao esforço de flexão não é amplamente explorada no Brasil, mesmo tendo ocorrido um crescimento considerável nas últimas décadas. Vigas com adição de fibras não é um método totalmente difundido no Brasil, entretanto pisos de concreto e lajes reforçados com fibras já são mais usuais nas construções do país Para análise do comportamento à flexão foram realizados ensaios de laboratório com oito corpos de prova, moldados com e sem fibras, a maioria com entalhe induzindo a propagação vertical da fissura na região central da viga. Foi utilizado um baixo teor de fibras de aço $(0,25 \%)$ para não implicar na trabalhabilidade do concreto e, com isso, testar um material que pode ser confeccionado em situações usuais da construção civil. Para o teor de fibras estudado observou-se um acréscimo de $26,6 \%$ no valor da carga máxima atingida. Outro fator relevante foi que não houve dificuldades em relação a trabalhabilidade do concreto quando adicionado as fibras. Os resultados obtidos sobre a resistência comprovaram eficiência quando se usou as fibras no ensaio a flexão.

ABSTRACT: The present work compares the results experimentally of four-point bending tests of concrete beams with and without addition of steel fibers. The main objective of this work was to analyze the influence of steel fibers in modifying the appearance of pathologies related to concrete cracking. This work is justified by the fact that the implementation of reinforcement elements to the flexion effort is not widely explored in Brazil, even though there has been a considerable growth in the last decades. Beams with addition of steel fibers are not method used in Brazil, however, concrete floors and fiberreinforced slabs are more common in the country's constructions. For bending behavior analysis, laboratory tests were performed with eight test specimens, molded with and without fibers, most of them with notch, inducing vertical propagation of the crack in the central region of the beam. It was use of a low content of steel fibers $(0,25 \%)$ to avoid the workability of the concrete and, with this, to test a material that can be made in usual civil construction situations. For the fiber content studied, there an increase of $26,6 \%$ in the maximum load value. Another relevant factor was that there were no difficulties in relation to the workability of the concrete when added the fibers. The results obtained on the resistance proved efficiency when the fibers were used in the bending test.

\footnotetext{
* Contato com o autor:

${ }^{1}$ e-mail: valquíria.santos@gmail.com (SANTOS V.C.)

Engenheira Civil, Doutora, Coordenadora do curso, UNIFEI - Universidade Federal de Itajubá.

2e-mail: paulocg9@yahoo.com.br (GONÇALVES P.C.)

Engenheiro Civil, Doutor, Professor, UNIFEI - Universidade Federal de Itajubá.

${ }^{3}$ e-mail: adinele@unifei.edu.br (GUIMARÃES A.G.)

Engenheira Civil, Doutora, Professora, UNIFEI - Universidade Federal de Itajubá.

${ }^{4}$ e-mail: felipe_caballer@hotmail.com (CABALLER F. O.)

Engenheiro Civil, Graduado.
} 


\section{INTRODUÇÃO}

O concreto, por si só, é reconhecido por sua versatilidade, já que é possível a sua utilização em estruturas de diversos formatos e tamanhos. Apesar de todo o progresso alcançado nos últimos anos, o concreto continua apresentando um comportamento frágil, com baixa resistência à tração, exigindo o uso de armaduras de reforço. Além disso, o concreto possui algumas deficiências como a dificuldade de ocupar totalmente peças esbeltas muito armadas, baixa ductilidade, retração plástica e permeabilidade em ambientes úmidos, que originam várias patologias. Tais carências motivou o desenvolvimento de várias pesquisas no âmbito experimental.

Com o desenvolvimento destes estudos e pesquisas, verificou-se que as matrizes cimentícias, de forma geral, podem adquirir diferentes comportamentos relacionados a resistência e ductilidade quando são utilizadas com diferentes fibras, de diversos materiais, tais como o aço, o carbono, o vidro, o polipropileno, o sisal, o coco, o bambu e as fibras minerais. Em elementos estruturais, dentre os diferentes tipos de fibras, as mais utilizadas são de aço. Este tipo de fibra apresenta um formato bastante variável com o intuito de elevar a sua aderência com a matriz cimentante.

Alguns pesquisadores veem estudando o comportamento das fibras no concreto sujeitas a esforços mecânicos. GARCEZ (2005) teve como objetivo a caracterização do comportamento mecânico básico e a determinação de ensaios de resistência com incorporação de fibras de aço com diferentes geometrias e em diferentes teores nos concretos. Como conclusão, verificou-se que a resistência à tração por compressão diametral é afetada positivamente pelo uso de agregados maiores e elevados teores de fibra, possivelmente devido à maior resistência à deformação e tenacidade dos compósitos com estas características.

O estudo de GAVA (2006) teve por objetivo principal a análise teórica e experimentalmente do comportamento da resistência após a fissuração de vigas de concreto reforçado com fibras de aço submetidas à flexão. Verificou-se também a validade de um modelo teórico-experimental que é baseado em ensaios de flexão de vigas para a obtenção de parâmetros relacionados à contribuição das fibras de aço nos esforços de tração.

FIGUEIREDO (2011) fez revisões críticas de trabalhos na área dos concretos reforçados com fibras (CRF). O trabalho de LOPES (2005) foi um estudo sobre a substituição parcial de armadura de flexão por fibras de aço em vigas de concreto. A partir da análise dos resultados experimentais apresentados, conclui-se que a substituição de parte da armadura de flexão por fibras de aço era possível.

As estruturas de concreto são suscetíveis a um inevitável estado de fissuração devido a sua natureza não homogênea, podendo levar a manifestações patológicas. Em razão de determinada proporção de abertura das fissuras e do ambiente a qual a estrutura se encontra inserida, agentes agressivos podem comprometer a sua durabilidade ou mesmo levar a sua ruína.

As fissuras são indesejáveis e antiestéticas, são patologias que geram gastos para efetuar os reparos necessários. Com o conhecimento da causa da fissura é possível tomar a decisão correta sobre o tipo de tratamento necessário. Em alguns casos, há a necessidade de executar reforços estruturais na peça fissurada e, em outros casos mais graves, a peça pode estar condenada. A adição de fibras de aço em concreto permite um maior controle do estado de fissuração na peça estrutural visa justamente o incremento da qualidade do material e diminuição do aparecimento de fissuras e rompimento nestas regiões patológicas.

\section{OBJETIVO}

O desenvolvimento do presente estudo tem como objetivo principal analisar a importância e as influências que as fibras de aço tendem em modificar o surgimento de patologias relacionadas a fissuração do concreto. Este trabalho aborda também as vantagens/desvantagens construtivas 
contribuindo assim para ampliar a implantação deste sistema estrutural. Para análise da influência das fibras foram realizados ensaios experimentais de flexão entre vigas de concreto com e sem fibras de aço.

\section{REVISÃO CONTEXTUALIZAÇÃO \\ BIBLIOGRÁFICA}

\subsection{TIPOS DE FIBRAS E MICROFISSURAS}

Existem muitos tipos de fibras de aço disponíveis, com diversas variações em suas geometrias. Para Figueiredo (2000) há três tipos mais comuns de fibras de aço disponíveis no mercado brasileiro:

A fibra de aço corrugada é produzida a partir de sobras da produção da lã de aço, com comprimentos que variam de $25 \mathrm{~mm}$ a $50 \mathrm{~mm}$ (Figura 1[a]). Este modelo apresenta aderência satisfatória com a matriz. Os outros dois modelos de fibras de aço são compostos por trechos retos de filamentos de aço associados a dobras (Figura 1[b] e $1[\mathrm{c}])$, promovendo uma ancoragem em gancho. Estes filamentos de aço apresentam seção circular ou plana (Figueiredo, 2000).

O Brasil conta com uma norma de especificação para as fibras de aço, a NBR 15530 (ABNT, 2007). Esta norma apresenta avanços no ramo das fibras de aço, visto que contribui com a determinação de uma tipologia e classificação das fibras, permitindo o estabelecimento de requisitos e tolerâncias específicas dos materiais utilizados.

A maior dificuldade na adição de fibras em matrizes cimentícias está baseada na redução da trabalhabilidade, devido ao fato de que as fibras são consideradas uma adição inerte, ocasionando o intertravamento da mistura. A redução de trabalhabilidade é consequência direta de características como geometria da fibra, traço do concreto, interface fibra-matriz, fração volumétrica adicionada ao fator de forma das fibras (ACl, 1996). Devido a tal fato, pode ser necessária uma adaptação na dosagem das matrizes, para que seja possível uma dispersão adequada das fibras, provando a hipótese da criação de uma rede tridimensional que esteja de acordo com as características homogêneas do compósito.

A dosagem de um concreto com fibras deve ser efetuada de maneira a resultar em uma trabalhabilidade que permita o correto lançamento, adensamento e acabamento com o mínimo de esforço, com segregação mínima do material, já que as misturas de concreto reforçado com fibras de aço apresentam uma tendência a gerar aglomerações de fibras, os chamados bolos ou novelos. Essas aglomerações resultam no enfraquecimento do material, uma vez que apenas nata de cimento será capaz de penetrar no seu interior, e dependem do diâmetro máximo e da granulometria do agregado, do fator de forma da fibra, da fração volumétrica de fibra e da maneira de introduzir a fibra na mistura.

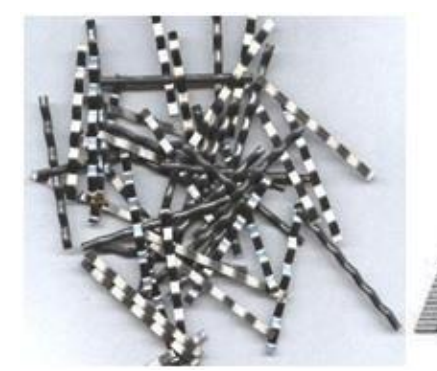

[a]

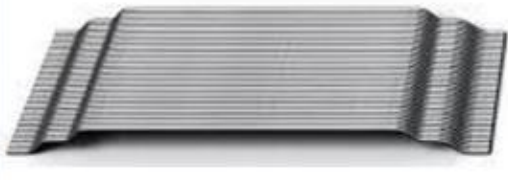

[b]

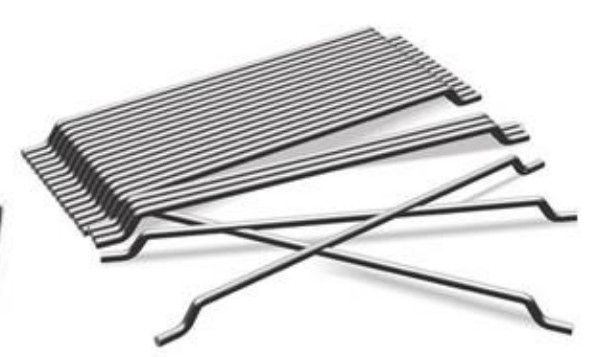

[c]

FIGURA 1: [a] Fibra de aço corrugada, [b] Fibra com Ancoragem em Gancho e Seção Retangular, [c] Fibra com Ancoragem em Gancho e Seção Circular.

FONTE: OM Construtora (2000). 
Embora a orientação das fibras seja muito sensível à trabalhabilidade, Boulekbache et al. (2016) demonstraram que os concretos auto adensáveis favorecem o alinhamento das fibras na direção paralela à direção da tração, obtendo a adequada eficiência das fibras

O bom comportamento da matriz cimentícia fica comprometido por sua limitada resistência à tração. Mehta e Monteiro (1994) afirmam que antes mesmo de ser submetido a tensões externas, o concreto desenvolve microfissuras na zona de transição entre a matriz e os agregados graúdos devido a sua natureza heterogênea, e pouca energia é necessária para que ocorra o aumento destas fissuras, justificando a ruptura frágil do material.

O problema, para Garcez (2005) é analisado do ponto de vista micro estrutural (micro escala). Neste ponto de vista, quando o concreto é submetido à tração ou à flexão, a energia se concentra principalmente nas extremidades das regiões de microfissuras existentes, como mostra a Figura 2a, causando a propagação das fissuras. Como consequência, há a ruína do material. Uma forma usual para se melhorar o desempenho à tração de matrizes frágeis consiste na adição de fibras às mesmas. As fibras agem como pontes de transferência de tensões, distribuindo as concentrações de tensões nas extremidades das fissuras, conforme mostra a Figura 2[b].

Em um concreto reforçado com fibras, o processo de fissuração ocorre com o surgimento de forças atrativas causadas pelas tensões de aderência desenvolvidas na interface fibra-matriz. A eficácia do concreto reforçado por fibras é fortemente influenciada pela capacidade de aderência entre as fibras e a matriz de cimento (RUANO, et al., 2014). Deste modo é necessária uma maior energia para que ocorra a abertura e propagação das fissuras e consequentemente, torna a ruína do material menos frágil, o que proporciona um teórico ganho de ductilidade na estrutura.

Para Garcez (2005), a primordial função das fibras no compósito é relacionada ao controle da fissuração, já que alteram comportamento do concreto a partir do aparecimento da primeira fissura. Segundo Boulekbache et al. (2016), com adição das fibras de reforço no concreto à flexão, percebe-se um significativo aumento do acúmulo de energia e consequente acréscimo da ductilidade antes da ruptura. Os resultados dos ensaios a flexão demonstraram um melhor comportamento póspico do material.

Uma característica importante da fibra de aço é o fator de forma: "este índice é capaz de indicar a eficiência da fibra para a melhora da tenacidade do compósito" (GARCEZ, 2005). O fator de forma é definido como a relação entre o comprimento da fibra e o diâmetro de uma circunferência virtual cuja área seria equivalente à seção transversal da fibra.

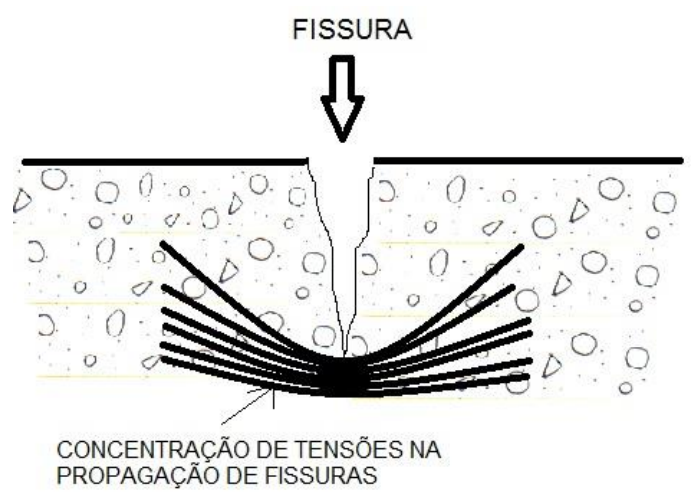

[a]

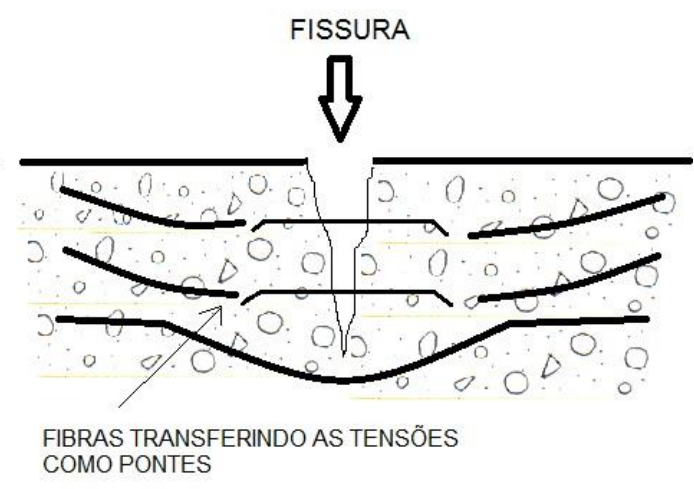

[b]

FIGURA 2: [a] Concentração de tensões na tração no extremo das microfissuras [b] Reforço de fibras que transferem as tensões das áreas de fissuração.

FONTE: Nunes e Agopyan (1998). 
Nunes e Agopyan (1998), ensaiando concretos reforçados com fibras de aço de mesmo comprimento e fatores de forma diferentes, mostraram que ocorre um aumento da tenacidade à flexão do compósito com o aumento do fator de forma, fato justificado pelo maior número de fibras presentes por unidade de volume da matriz. Entretanto, os autores ressaltam que a influência do fator de forma é menos significativa do que a influência do consumo, ou teor total, de fibras.

o comprimento crítico é uma característica também relevante, sendo definido como sendo o menor comprimento necessário para o desenvolvimento de tensões nas fibras, equivalente à sua resistência (BENTUR e MINDESS, 1990). Quando o comprimento da fibra embutido na matriz é menor do que o comprimento crítico, a ancoragem não é capaz de gerar tensões de escoamento ou de ruptura nas fibras. Segundo Garcez (2005), com o acréscimo da deformação e, consequentemente, da abertura da fissura, a fibra que está atuando como ponte de transferência de tensões será arrancada de forma fácil do lado que possuir o menor comprimento embutido. Em outra situação, quando o comprimento da fibra embutido na matriz é superior ao comprimento crítico, há o travamento da fibra, que impossibilita o seu arrancamento e ocasiona uma elevada tensão que atua na fibra, até que seja atingida uma tensão de ruptura.

Entretanto, segundo alguns autores, quando o comprimento médio das fibras empregadas é igual ao comprimento crítico, obtémse a máxima tenacidade do compósito. Porém para Garcez (2005), estas ideias são fundamentalmente teóricas, já que não é possível realizar uma previsão de onde ocorrerá a fissura em relação ao comprimento da fibra, além do fato de que as suas duas extremidades não estarão, necessariamente, ancoradas da mesma maneira. Haitang et al. (2018) investigaram a influência da espessura da camada e da fração do volume de fibras em barras de aço como reforço em concreto de alta resistência e observaram que os efeitos na capacidade resistente a flexão não foram altamente significantes, porém contribuíram para diminuição proporcional da deformação e controle da abertura das fissuras.

Como explica Chen et al. (1994) a direção de propagação de uma fissura é normal à direção da tensão principal máxima. Neste contexto, para um estado de fissuração generalizado associa-se um estado degenerativo da estrutura, com redução brusca da resistência e consequentemente levando ao colapso. Portanto, o mecanismo de ruptura na tração se desenvolve por meio da união de fissuras pré-existentes ou desenvolvidas desde os primeiros estágios de carga, diferentemente do que acontece no estado de ruptura por tensões de compressão, que considera $\mathrm{o}$ aparecimento de numerosas fissuras independentes.

Este fenômeno evidencia que a direção de posicionamento das fibras inseridas no concreto não deve ser aleatória, mas estar em concordância com o sentido da tensão principal de tração, garantindo melhor desempenho do compósito. No caso do concreto, em geral, é mais comum haver uma distribuição aleatória e homogênea de seus componentes, formando um reticulado tridimensional não orientado, porém, fibras muito longas, podem tender a se orientar aleatoriamente durante o processo de lançamento e compactação, ou seja, não há garantias de eficiência das fibras nestes casos. Kan e Kin (2012) verificaram que a eficácia das fibras reduz em até $70 \%$ quando dispostas aleatoriamente quando comparadas com as fibras alinhadas paralelas a direção principal máxima.

Em situações de concretos com mínima e razoável resistência mecânica, a propagação da fratura é localizada na região da interface entre o agregado graúdo e a pasta. A fibra tem objetivo de servir como ponte de transferência das tensões nas fissuras, mas para isso, seu comprimento precisa ser suficiente para facilitar uma posição eficiente nesta interface. Normalmente, este comprimento necessita ser superior a duas vezes a dimensão máxima do agregado (GARCEZ 2005).

Segundo GAVA (2006), em muitos trabalhos relacionados sobre vigas com entalhe para o ensaio de flexão do concreto reforçado com fibras de aço, não há um consenso sobre as dimensões do entalhe. Gopalaratnam et al. (1995) 
empregaram uma relação entre a altura do entalhe e altura da viga da ordem de 0,125. Jamet et al. (1995) apresenta uma relação de 0,275. A norma americana RILEM TC 162-TDF (2000) recomenda que, para vigas de $150 \times 150 \times 550 \mathrm{~mm}^{3}$, com 450 $\mathrm{mm}$ de vão, o entalhe deve possuir uma altura de 25 $\mathrm{mm}$ e uma espessura de $3 \mathrm{~mm}$, que resulta em uma relação de alturas de mais ou menos 0,2. Bem diferente de Taylor et al. (1997), que utilizaram vigas de $100 \times 100 \times 500 \mathrm{~mm}^{3}$ com entalhe de $50 \mathrm{~mm}$ de altura, ou seja, uma relação altura do entalhe por altura da viga de 0,5.

Ghasemi et al. (2018) investigaram o efeito do tamanho do agregado graúdo nos parâmetros de fratura em concretos de auto adensamento reforçados com fibras de aço a partir de ensaios a flexão a três pontos de vigas com entalhes. Ghasemi et al. (2018) empregaram os parâmetros recomendados pelo RILEM TC 162-TDF (2000), cuja relação comprimento do entalhe e altura da seção transversal foi de 0,2.

\section{METODOLOGIA}

\subsection{MATERIAIS UTILIZADOS PARA O CONCRETO}

Para o desenvolvimento desse estudo foram preparado quadro vigas de concreto utilizadas como referência e quadro vigas de concreto com adição de fibra de aço. Os corpos de prova com fibras tiveram sua adição de forma aleatória. Após a adição, passou-se para fase de adequada homogeneização do concreto para posterior preenchimento das formas dos corpos de prova. As formas preenchidas foram armazenadas em câmara úmida até o momento de desmolde e identificação. Em seguida, para que o concreto atingisse a sua resistência característica, as vigas foram mantidas em processo de cura por um período total de 28 dias, até a data dos ensaios. Nesse estudo foram utilizados os seguintes materiais constituintes dos concretos: cimento CP II E 32, areia natural, brita natural, fibras de aço e água.

O cimento Portland CP-II E 32 apresentou massa específica de $3,150 \mathrm{~g} / \mathrm{cm} 3$ determinada de acordo com a NBR NM:23 (ABNT, 2001). Os agregados miúdos foram caracterizados como areia média conforme NBR NM:248 (ABNT, 2003), com diâmetro dos grãos entre 0,42 e $2,0 \mathrm{~mm}$ e massa específica de $2,238 \mathrm{~g} / \mathrm{cm}^{3}$ conforme a NBR NM:52 (ABNT, 2009). Os agregados graúdos foram caracterizados conforme NBR NM:248 (ABNT, 2003) com dimensões de 9,5 mm e $19 \mathrm{~mm}$. Todos os corpos de prova reforçados com fibras empregaram Fibras Wirand FF4 (Figura 3), cedidas pela empresa Maccaferri. Estas fibras possuem as seguintes características:

- Diâmetro: 0,75 mm;

- Comprimento: $60 \mathrm{~mm}$;

- Fator de Forma: 80;

- Classificação: A1, pela ABNTNBR 15530 (2007).

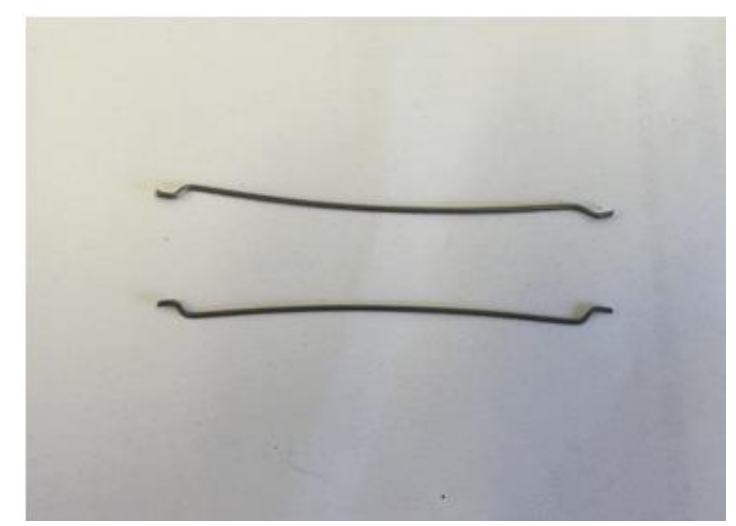

FIGURA 3: Fibras de aço utilizadas. FONTE: Autoria Própria

Foram produzidos oito corpos de prova com as dimensões de $15 \times 15 \times 50 \mathrm{~cm}$, o volume total de concreto a ser produzido foi de $0,09 \mathrm{~m}^{3}$, para este total as quantidades de materiais utilizados são mostrados na Tabela 1.

TABELA 1: Quantitativos dos materiais usados na confecção do concreto

\begin{tabular}{|c|c|c|c|c|}
\hline Material & Cimento & Areia Média & Brita 1 & Água \\
\hline Quantidades & $32,16 \mathrm{~kg}$ & $77,22 \mathrm{~kg}$ & $76,54 \mathrm{~kg}$ & $12,72 \mathrm{~L}$ \\
\hline
\end{tabular}


Para procedimentos de moldagem do concreto foram seguidas as orientações da norma NBR 5738 (ABNT, 2003). Após a moldagem dos corpos de prova sem fibras de aço, continuou-se o processo de misturado concreto, agora com a adição de forma aleatória das fibras. As fibras foram adicionadas manualmente à mistura, com a betoneira em movimento, para evitar a formação de grumos de fibras. Após a adição, deixou-se a betoneira ligada por mais três minutos, até a sua completa homogeneização no concreto. Passado este tempo, as formas para moldagem dos corpos de prova com fibras foram preenchidas, conforme orientações normativas.

Segundo o American Concrete Institute (1993), teor usual de emprego de fibras de aço em concreto varia entre $0,25 \%$ e $2 \%$ em relação ao volume, isto corresponde a aproximadamente 20 $\mathrm{kg} / \mathrm{m}^{3}$ e $157 \mathrm{~kg} / \mathrm{m}^{3}$, respectivamente. Já para Naaman (2000), o teor típico de fibra sem concreto comum é sempre inferior a $2 \%$ em volume. Baseando-se nestes valores e, considerando uma trabalhabilidade aceitável, sem a necessidade de mudança da dosagem do concreto, adotou-se o valor de $20 \mathrm{~kg} / \mathrm{m}^{3}$ de fibras de aço em cada corpo de prova do ensaio. Assim é possível analisar as diferenças no comportamento das vigas sob flexão em casos que há um baixo teor de fibras de aço, hipótese ideal para a confecção destes compósitos na prática, como em obras, visto que demanda de um material fácil de ser produzido e trabalhado.

Considerando o teor de $20 \mathrm{~kg} / \mathrm{m}^{3}$ e o volume total de quatro corpos de prova:

$(0,15 \times 0,15 \times 0,50) \mathrm{m} \times 4=0,045 \mathrm{~m}^{3}$

Tem-se que a quantidade de fibras adicionadas foi de:

$0,045 \mathrm{~m}^{3} \times 20 \mathrm{~kg} / \mathrm{m}^{3}=0,9 \mathrm{~kg}$.

O ensaio de flexão a quatro pontos foi realizado na máquina universal. Neste ensaio a norma NBR 12142 (ABNT, 2010) sugere que o comprimento da viga seja igual a três vezes o valor da distância dos cutelos de aplicação da força. Já a seção transversal da viga deve ser quadrada e possuir os lados com a mesma dimensão desta distância dos cutelos.

O aplicador de força disponível no
Laboratório de Materiais de Construção Civil da UNIFEI - Universidade Federal de Itajubá possui cutelos separados em $20 \mathrm{~cm}$, o que indica um corpo de prova com as dimensões de $20 \times 20 \times 60 \mathrm{~cm}^{3}$. Porém, devido a restrições das dimensões da máquina de ensaio de flexão, a seção transversal máxima possível foi de $15 \times 15 \mathrm{~cm}^{2}$. Com isso, optouse de testar corpos de prova com as dimensões de $15 \times 15 \times 50 \mathrm{~cm}^{3}$, dimensões condizentes com a norma americana RILEM TC 162-TDF (2000), que estabelece seções transversais de $15 \times 15 \mathrm{~cm}^{2}$, com $45 \mathrm{~cm}$ de vão entre os apoios.

Oito vigas foram confeccionadas, a numeração dos corpos de prova para identificação foram: de 1 a 4 as vigas sem fibras de aço e de 5 a 8 com fibras de aço.

As vigas 1 e 5 foram testadas com velocidade de $1 \mathrm{MPa} / \mathrm{s}$, sem a confecção dos entalhes, com objetivos de apresentarem um panorama destas características, determinação de sua viabilidade e verificação dos dados revisados na bibliografia sobre testes semelhantes.

Para as demais vigas o ensaio foi ajustado e padronizado, com a confecção dos entalhes e velocidade de 0,5 MPa/s. A velocidade do ensaio foi alterada para o restante das vigas, passando de 1 $\mathrm{MPa} / \mathrm{s}$ para $0,5 \mathrm{MPa} / \mathrm{s}$, devido a limitação da máquina universal e visando uma melhor representação gráfica dos resultados.

Alguns autores indicam que há necessidade de utilizar vigas com entalhes, induzindo a propagação vertical da fissura na região central da viga, sendo este o comportamento esperado em ensaios de vigas sob flexão pura.

A confecção do entalhe por meio de corte é mais eficaz, visto que evita a acumulação das fibras na região do entalhe, o que pode causar uma superestimação da tenacidade do concreto reforçado pelas fibras de aço. Em outras palavras, há uma impressão de resistência superior no entalhe do que no restante da viga.

Robins et al. (2001) verificaram via experimentação, que a maioria das vigas que possuíam o entalhe na região central rompeu no local do entalhe. Já nas vigas que não possuíam entalhe o surgimento das fissuras ocorre de forma 
aleatória, podendo apresentar certa dispersão dos resultados de ensaios. Soma-se a isso, o fato de que a fissura não ocorre no meio do vão e a leitura do deslocamento é feita nesta região, ocasionando um valor de deslocamento medido menor do que o valor do deslocamento real, uma vez que o máximo deslocamento ocorre no local da fissura.

Neste estudo, decidiu-se utilizar o entalhe em três, das quatro vigas de cada tipo, (vigas 2, 3, 4, 6, 7 e 8) possibilitando uma averiguação dos conceitos teóricos. Estes entalhes foram feitos após a cura do concreto das vigas, com ferramenta de serra elétrica, com discos próprio para concreto e seguiram as recomendações da norma americana RILEM TC 162-TDF (2000), que propõem um entalhe com altura de $25 \mathrm{~mm}$ e uma espessura de $3 \mathrm{~mm}$, resultando em uma relação de alturas de 0,167.

\section{RESULTADOS OBTIDOS E ANÁLISES}

\subsection{RESISTÊNCIA DAS VIGAS ENSAIADAS}

As vigas sem fibras de aço foram ensaiadas a flexão sob quatro pontos, na Tabela 2 observa-se os resultados da velocidade de ensaio, carga máxima atingida, que corresponde a ruptura e surgimento da primeira fissura, deslocamento no momento de ruptura e o local que ocorreu a fissura.

0 ensaio do teste realizado na viga 1 , com uma velocidade superior aos demais, foi o que mais apresentou resistência em relação à carga aplicada, fato que já era esperado, devido a ausência do entalhe. Este valor foi $21 \%$ superior à média obtida em relação às vigas 2,3 e 4.

A média dos deslocamentos no momento de ruptura foi de $0,276 \mathrm{~mm}$, valor muito reduzido, indicando baixa ductilidade do material e, consequentemente, baixa resistência relacionada a tração causada pela flexão.

O local de fissura, no teste sem a presença de entalhes, foi aleatório, conforme afirmam autores que estudaram estes comportamentos, como Jamet et al. (1995), Barr et al. (1996) e Robins et al. (2001). Com isso, não seria possível medir o deslocamento máximo no momento de ruptura, já que ocorreria no local aleatório da fissuração. As curvas de carga $x$ deformação obtiveram padrões semelhantes, conforme indica a Figura 4.

O valor do carregamento dos quatro ensaios se desenvolveu de forma constante, com uma angulação de aproximadamente 40 ㅇ em relação ao plano horizontal até a ruptura. Após este instante, o decréscimo apresentou angulação de 70 ㅇ, comportamento de fissuração típico de concretos sem adição de fibras de aço, conforme mencionou Bentur e Mindess (1990).

A Tabela 3 resume os resultados obtidos com os corpos de prova que receberam adição de fibras de aço.

\begin{tabular}{|c|c|c|c|c|}
\hline \multicolumn{7}{|c|}{ TABELA 2: Resultados Vigas sem fibras de aço } \\
Viga & $\begin{array}{c}\text { Velocidade } \\
\text { de Ensaio } \\
(\mathrm{MPa} / \mathrm{s})\end{array}$ & $\begin{array}{c}\text { Carga Máxima } \\
(\mathrm{KN})\end{array}$ & $\begin{array}{c}\text { Deslocamento } \\
\text { momento } \\
\text { Ruptura }(\mathrm{mm})\end{array}$ & Local da Fissura (cm) \\
\hline 1 & 1 & 19,65 & - & $\mathrm{x}=13$ \\
\hline 2 & 0,5 & 16,55 & 0,28 & $\mathrm{x}=25$ (Entalhe) \\
\hline 3 & 0,5 & 14,85 & 0,32 & $\mathrm{x}=25$ (Entalhe) \\
\hline 4 & 0,5 & 17,25 & 0,23 & $\mathrm{x}=25$ (Entalhe) \\
\hline
\end{tabular}

FONTE: Autoria Própria 


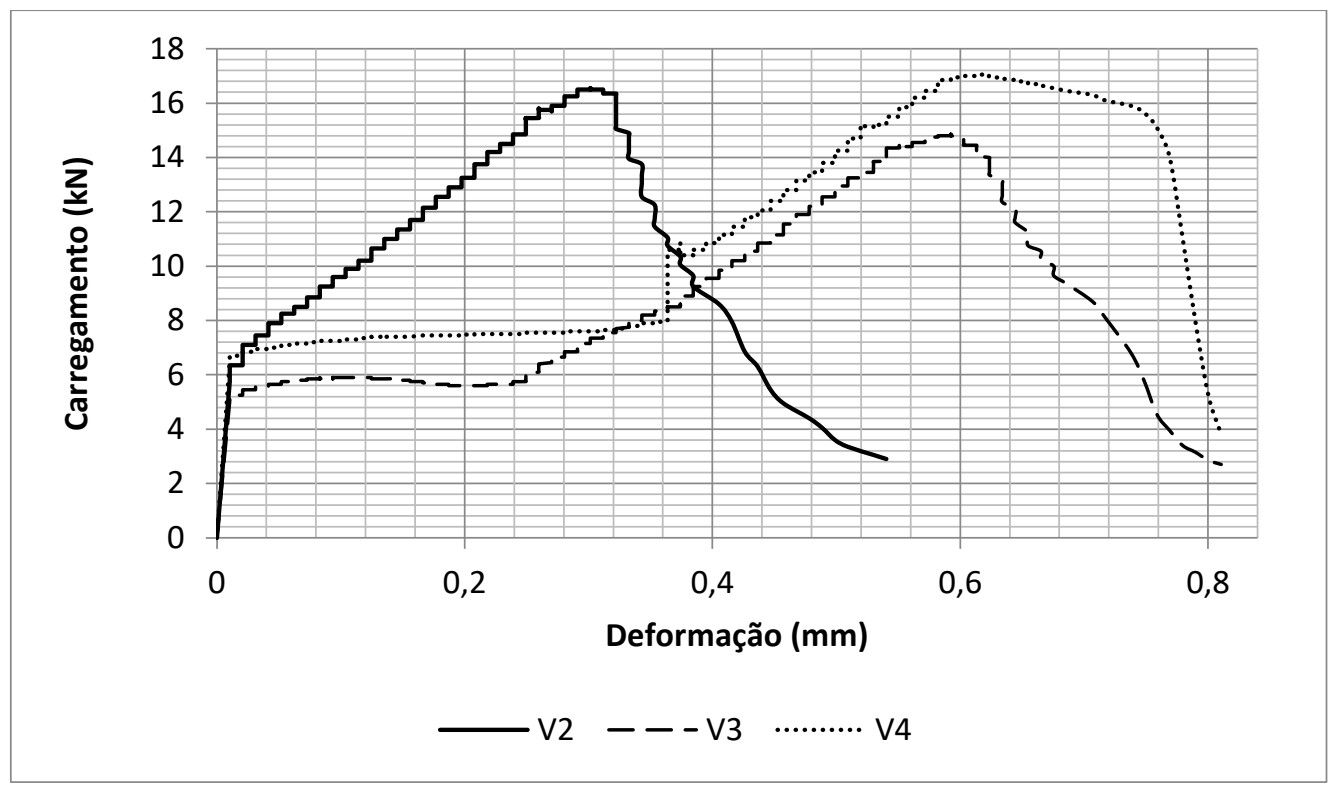

Figura 4: Gráfico carga x deformação vigas sem fibras de aço.

FONTE: Autoria Própria

\begin{tabular}{|c|c|c|c|c|c|}
\hline \multicolumn{6}{|c|}{ TABELA 3: Resultados Vigas com fibras de aço } \\
\hline Viga & $\begin{array}{l}\text { Velocidade de } \\
\text { Ensaio (MPa/s) }\end{array}$ & $\begin{array}{c}\text { Carga } \\
\text { Máxima (KN) }\end{array}$ & $\begin{array}{l}\text { Tempo de } \\
\text { Ensaio (s) }\end{array}$ & $\begin{array}{l}\text { Deslocamento } \\
\text { momento Ruptura } \\
\text { (mm) }\end{array}$ & Local da Fissura $(\mathrm{cm})$ \\
\hline 5 & 1 & 26,5 & 182,47 & - & $x=30,5$ \\
\hline 6 & 0,5 & 20,75 & 297,2 & 0,45 & $x=25$ (Entalhe) \\
\hline 7 & 0,5 & 17,55 & 248,71 & 0,68 & $x=25$ (Entalhe) \\
\hline \multirow[t]{2}{*}{8} & 0,5 & 21,7 & 244,55 & 0,77 & $x=25$ (Entalhe) \\
\hline & Média & 21,62 & 243,23 & 0,63 & \\
\hline
\end{tabular}

Novamente, a viga sem entalhe apresentou o maior valor de carga máxima, sendo $32,5 \%$ superior aos demais. A média dos deslocamentos no momento de ruptura foi de 0,63 $\mathrm{mm}$, valor razoável, que indica uma nova ductilidade do material relacionada a adição de fibras de aço. Confirmando o que afirma Gamino (2003), já que, com uma maior ductilidade, o concreto pode experimentar deformações inelásticas sem a redução de sua capacidade resistente, atingindo a ruptura somente após um maior acumulo de energia, ou seja, o concreto atinge uma maior capacidade de se deformar antes que a ruptura ocorra.

Pode-se destacar também que todos os resultados de carga máxima, tempo de ensaio e deslocamento no momento da ruptura, principalmente em relação aos ensaios uniformes, apresentaram resultados semelhantes, com baixo desvio padrão, possibilitando a constatação de que todos os testes foram executados de forma padrão, atentando-se pelas recomendações estabelecidas pelas normas em questão.

Segundo Bentur e Mindess (1990), quando são utilizados teores baixos de fibras, como nestes casos, há certas mudanças no comportamento plástico e na tenacidade do compósito, visível pelo alongamento da curva tensão $x$ deformação, graças ao maior controle da abertura das fissuras no estágio pós-fissuração. As curvas de carga $x$ deformação indicam exatamente este comportamento, além de obterem padrões semelhantes entre si, conforme indica a Figura 5. 


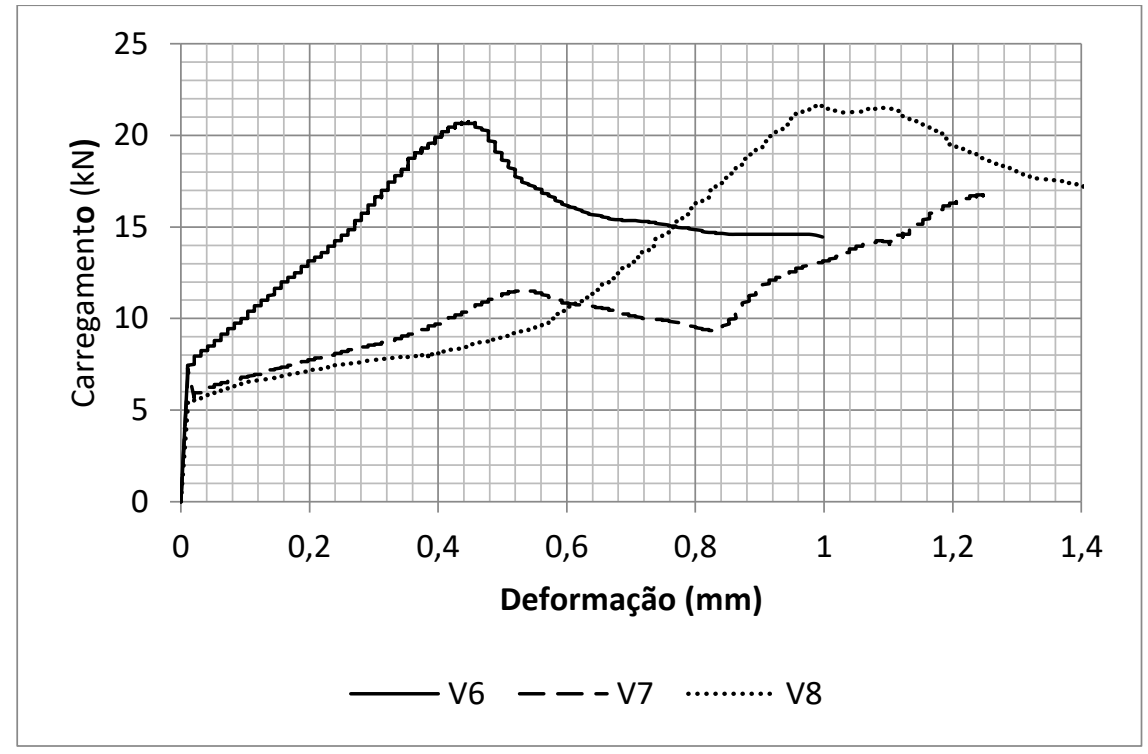

Figura 5: Gráfico carga x deformação vigas com fibras de aço. FONTE: Autoria Própria

O valor do carregamento dos ensaios se desenvolveu de forma constante, com uma angulação de aproximadamente 60 em relação ao plano horizontal até a ruptura. Após este instante, 0 decréscimo apresentou angulação média de $50^{\circ}$, indicando a presença de um baixo teor de fibras de aço $\left(20 \mathrm{~kg} / \mathrm{m}^{3}\right)$ no comportamento da fissuração, conforme a bibliografia já mencionada de Bentur e Mindess (1990).

\subsection{LOCALIZAÇÃO DAS FISSURAS NAS VIGAS ENSAIADAS}

Após a ruptura da viga 1 verificou-se que a fissura surgiu entre os apoios, fora do terço médio, com uma distância de $13 \mathrm{~cm}$ da extremidade esquerda. Para melhor visualização, fez-se um traçado com caneta vermelha sobre a fissura, indicando com exatidão a sua localização (Figura 6).

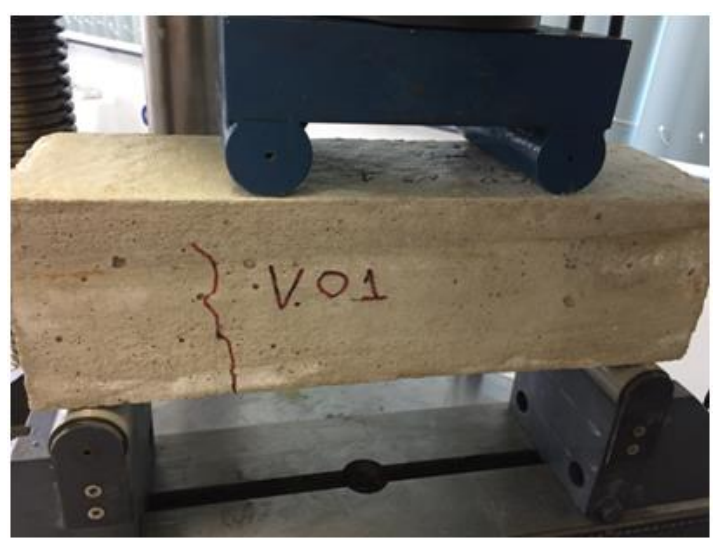

FIGURA 6: Fissura da viga 1. FONTE: Autoria Própria
O local da ruptura está de acordo com que afirma Robins et al. (2001), ou seja, sem entalhe, não há um lugar específico para o surgimento da fissura. $O$ fato deste local ser aleatório, impossibilita a medição do deslocamento, visto que a leitura é feita a região central da peça, ocasionando um valor de deslocamento medido menor do que o valor do deslocamento real, uma vez que o máximo deslocamento ocorre no local da fissura.

O entalhe na região central da viga impõe uma seção transversal menor, levando a ruptura nesta região. Este fato permitiu instalar o medidor de deslocamento na seção central das vigas para os demais ensaios, conforme indicado na Figura 7.

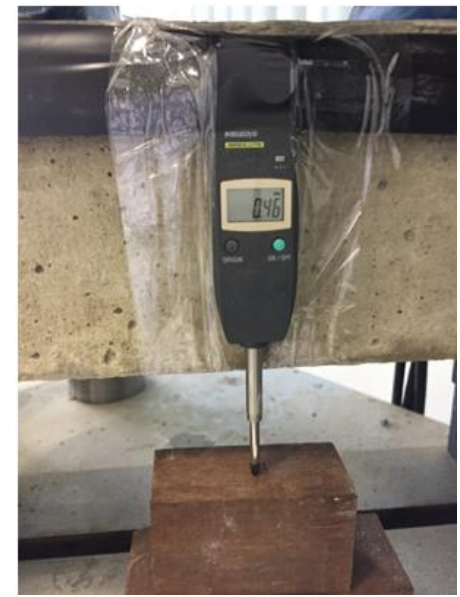

FIGURA 7: Medidor de deslocamento posicionado. FONTE: Autoria Própria

$\mathrm{Na}$ Figura 8 pode-se verificar a trajetória da propagação da fissura (em destaque) nas vigas 2 , 3 e 4 de concreto sem fibra de aço. 


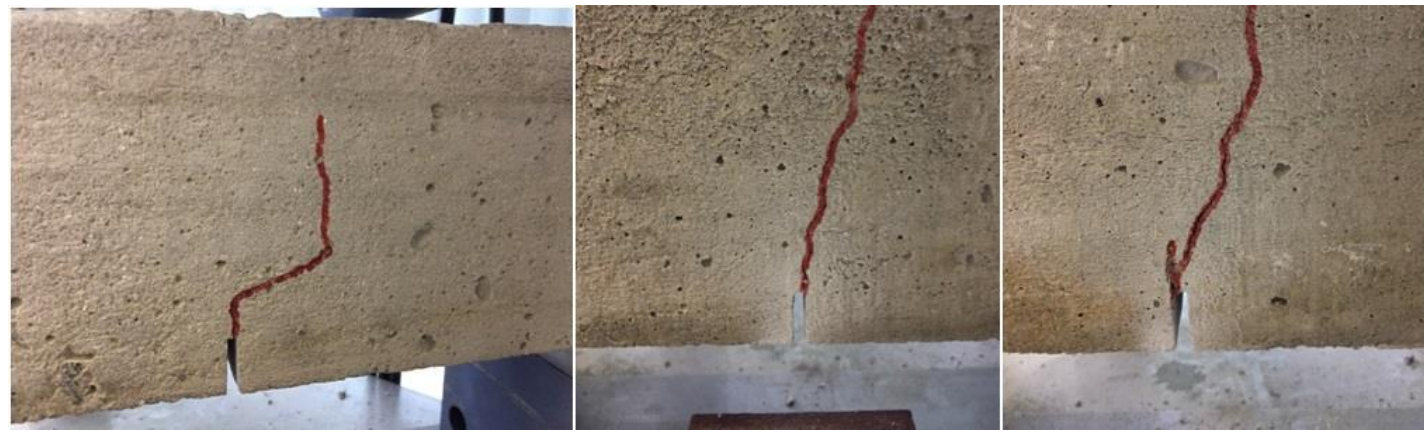

FIGURA 8: Trajetória das fissuras destacadas nas vigas 2,3 e 4 (concreto sem fibra de aço). FONTE: Autoria Própria

Após a ruptura da viga 5 (de concreto com fibra de aço sem entalhe), verificou-se que a fissura surgiu entre os apoios, dentro do terço médio, com uma distância de $30,5 \mathrm{~cm}$ da extremidade esquerda, conforme indica a Figura 9.

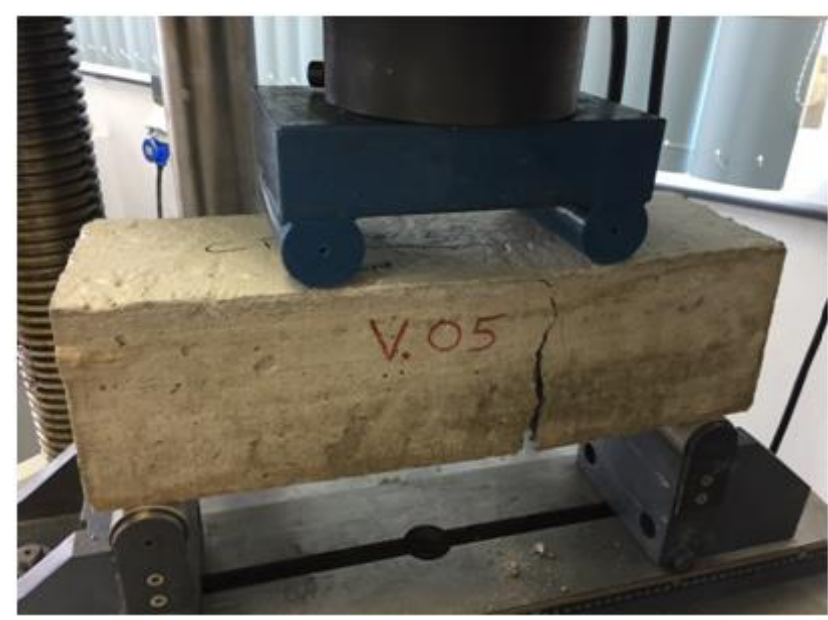

FIGURA 9: Momento da fissura Viga 5. FONTE: Autoria Própria

Para verificar o comportamento da viga após a fissuração e possibilitar a visualização das fibras nestes casos, permitiu-se a continuação da aplicação de força sobre o corpo de prova após a ruptura, ocasionando uma fratura considerável de $2,0 \mathrm{~cm}$. A Figura 10 ilustra a ruptura na parte inferior da vista, onde é possível a constatação das fibras de aço no momento que atuam como pontes de tensão.

Percebe-se também para as vigas 6, 7 e 8 (concreto com fibras de aço) que o comportamento dos valores novamente seguiu o padrão esperado por Bentur e Mindess (1990) para concretos com adição de um baixo teor de fibras de aço $(20 \mathrm{~kg} / \mathrm{m3})$. Karihaloo e Vriese (1999), citado por Bentur e Mindess (1990), utilizaram 4\% de fibra do volume de concreto e tiveram um aumento $21 \%$ na resistência a compressão, similarmente Sun et al. (2003), também citado por Bentur e Mindess (1990), encontraram um aumento de $33 \%$ com $4 \%$ de fibra. No presente trabalho foi encontrado um aumento de resistência a flexão de $27 \%$ com a porcentagem de $0,25 \%$ de fibra por volume de concreto. $O$ valor do carregamento se desenvolveu de forma praticamente constante até o momento de ruptura com uma angulação mais vertical, que indica uma menor velocidade da deformação em relação ao acréscimo de carga. Além de decrescer, após a ruptura, de forma mais horizontal, indicando o momento que as fibras de aço atuam como pontes de tensões. Após a ruptura da peça, verificou-se que a fissura realmente surgiu no centro, no local do entalhe, conforme mostrado na Figura 11.

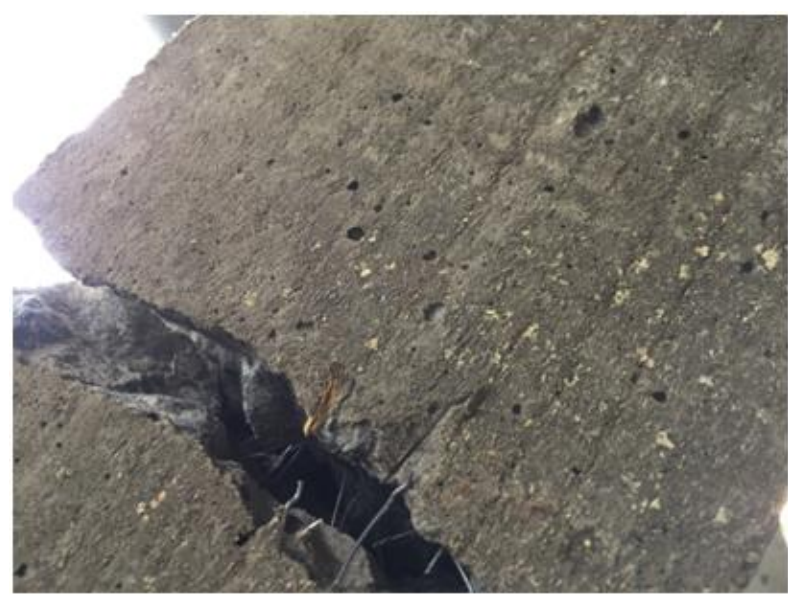

FIGURA 10: Detalhe da fissura Viga 5. FONTE: Autoria Própria 


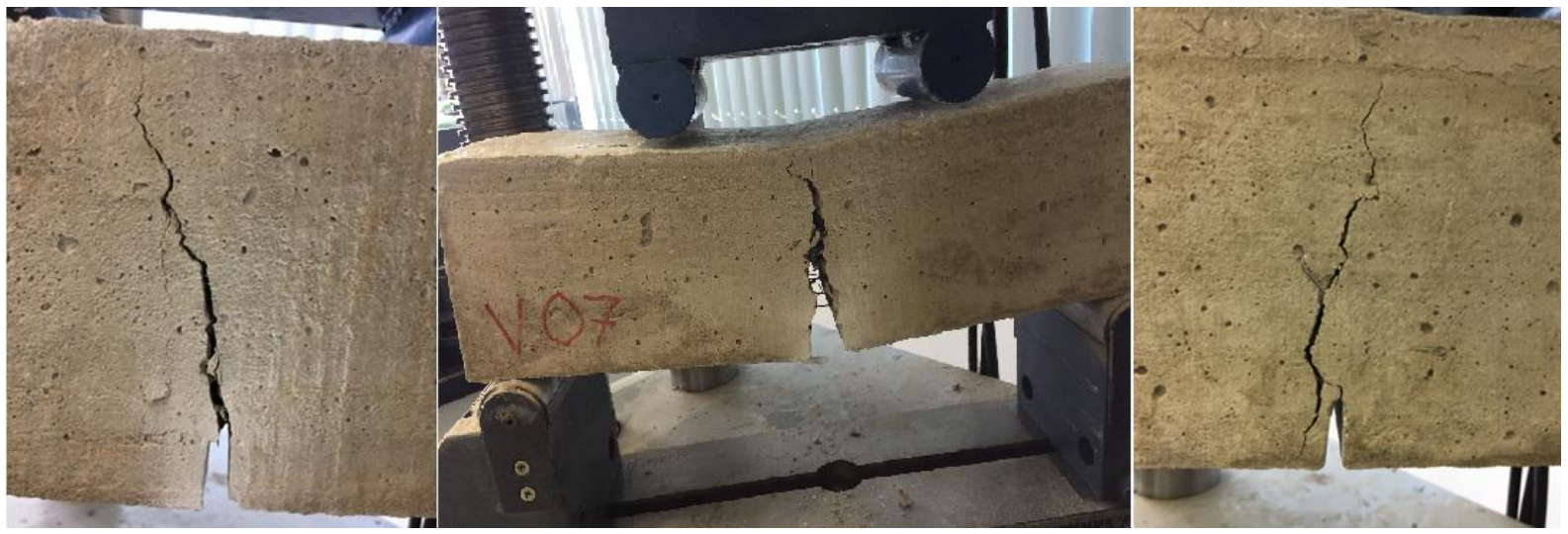

FIGURA 11: Detalhe da fissura das vigas 6,7 e 8 (concreto com fibras de aço).

FONTE: Autoria Própria

Este aumento encontra-se de acordo com as razões apresentadas por GHASEMI et al. (2018), para o comportamento inverso do módulo de elasticidade e da resistência à compressão com a quantidade de fibras. As razões apontadas por eles são: (1) quando aumenta o teor de fibras a resistência à compressão pode diminuir dependendo de como as fibras são distribuídas; em grandes volumes, as fibras podem estar alinhadas com a força aplicada e agir como vazios, que são os pontos de partida para microfissuras que causam a redução da resistência no concreto e (2) é possível que as fibras sejam acumuladas em um ponto devido à distribuição inadequada no molde e causar microfissuras a partir deste ponto de concentração.

\subsection{ANÁLISE DOS RESULTADOS}

Comparando os resultados obtidos, podese constatar que a média do pico de carga apresentado nos ensaios de vigas com fibras de aço é $26,6 \%$ superior em relação às vigas sem fibras de aço. Tal valor é consideravelmente alto, visto que o teor de fibras adicionados no compósito foi de apenas 0,25\% em relação ao volume, índice mínimo, segundo o American Concrete Institute (1993).

O motivo plausível deste incremento de resistência é relacionado ao aumento da ductilidade que as fibras provocam no material, já que materiais mais dúcteis apresentam maior dificuldade em romper devido à tração. Esta mudança nas características do material é comprovada pelo aumento do deslocamento máximo no momento de ruptura, que passou de $0,276 \mathrm{~mm}$ para $0,630 \mathrm{~mm}$, ou seja, um acréscimo de $128 \%$, valor bem expressivo para confirmação desta tese.

Os ensaios de flexão das vigas apresentaram razoável variabilidade. Os coeficientes de variação dos ensaios eram, em média, de 7,5\%, com valores máximos de $18,2 \%$, o que gerou satisfação na quantidade de amostras adotadas, ou seja, quatro corpos de prova por material.

Um resultado expressivo deste estudo foi o deslocamento ocasionado pela carga de flexão nas vigas obtidas em teste. O aumento de $128 \%$ nos compósitos com fibras confirma a tese de aumento de ductilidade do material. Segundo Gamino (2003), com uma maior ductilidade, o concreto pode experimentar deformações inelásticas sem a redução de sua capacidade resistente, atingindo a ruptura somente após um maior acumulo de energia, ou seja, o concreto atinge uma capacidade de se deformar antes que a ruptura ocorra.

Os estudos de BOULEKBACHE et al. (2016) também mostraram que o uso de fibras de aço no concreto melhora a resistência à flexão. Estes autores obtiveram nos seus experimentos um aumento na resistência à flexão de $242 \%, 174 \%$ e $150 \%$, em comparação com a amostra de concreto simples, para as amostras reforçadas com $1 \%$ de fibras com fator de forma 80, respectivamente, para Concreto Auto Adensável, Concreto de AltaResistência e Concreto Reforçado.

Nos testes com fibras de aço, o valor do carregamento se desenvolveu de forma praticamente constante até o momento de ruptura com uma angulação mais vertical, que indica uma menor velocidade da deformação em relação ao 
acréscimo de carga. Além de decrescer, após a ruptura, de forma mais horizontal, indicando o momento que as fibras de aço atuam como pontes de tensões.

A incorporação das fibras indicou interferências nas propriedades dos compósitos tanto nos estados fresco, quanto no endurecido. Teoricamente, no estado fresco, a incorporação de fibras poderia ocasionar perdas significativas de trabalhabilidade, fato não presenciado neste trabalho, visto o baixo teor de fibras. No estado endurecido, a influência foi significativa no desempenho dos compósitos, ocasionando melhoras significativas relacionadas a resistência do elemento, quando submetido a cargas de flexão.

\section{CONCLUSÕES}

Com os resultados obtidos nos ensaios experimentais deste trabalho, é possível observar algumas evidências e constatações sobre o comportamento do concreto reforçado com fibras de aço, quando submetido a cargas de flexão.

Para a obtenção e êxito dos resultados, foi necessária a definição dos procedimentos e materiais a serem empregados nos ensaios, conforme descritos no trabalho, com devidos cuidados no sentido de obter dados experimentais confiáveis e que representem o real valor dos materiais investigados. Dentre estes procedimentos, os principais cuidados foram relacionados a confecção do concreto, adição das fibras uniformemente, sem a criação de grumos em locais específicos, preparação da máquina universal de testes, com o posicionamento correto dos corpos de prova e devida instalação do aparato medidor de deslocamentos.

Em relação à obtenção de um concreto pretendido, seguiram-se recomendações detalhadas de Rodrigues (2003), com uma atenção especial a quantidade de umidade presente na areia usada como agregado miúdo. O resultado foi um concreto com uma resistência relevante, com trabalhabilidade suficiente para fácil preenchimento das formas. A equidade das dimensões dos corpos de prova foi garantida por um processo de verificação de suas dimensões e bom adensamento do concreto. As fibras escolhidas foram as mais comuns encontradas no mercado, sua adição foi empregada de forma a apresentar perfeita homogeneização do compósito e não surgimento de ar no interior do concreto.

Com estas características positivas obtidas experimentalmente, pode-se recomendar o uso dos concretos reforçados com fibras em diversas áreas da construção civil. O mais comum nos dias atuais é a utilização deste compósito em pisos, visto o aumento da ductilidade e de sua resistência relacionada a impactos. Porém, a utilização em elementos estruturais é igualmente viável, com uma redução e retardamento considerável no aparecimento de algumas patologias do concreto, como a fissuração, motivo de preocupação em executores e usuários de qualquer construção.

\section{REFERÊNCIAS BIBLIOGRÁFICAS}

ASSOCIAÇÃO BRASILEIRA DE NORMAS. NBR - NM23 (2001): Concreto - Cimento Portland e outros materiais em pó - Determinação da massa específica. Rio de Janeiro, 2001.

ASSOCIAÇÃO BRASILEIRA DE NORMAS. NBR - NM248 (2003): Agregados - Determinação da composição granulométrica. Rio de Janeiro, 2003.

ASSOCIAÇÃO BRASILEIRA DE NORMAS. NBR - NM52 (2009): Agregado miúdo - Determinação da massa específica e massa específica aparente. Rio de Janeiro, 2009.

ASSOCIAÇÃO BRASILEIRA DE NORMAS. NBR - $\mathbf{5 7 3 8}$ (2015): Concreto - Procedimento para moldagem e cura de corpos de prova. Rio de Janeiro, 2015.

ASSOCIAÇÃO BRASILEIRA DE NORMAS. NBR - 12142 (2010): Concreto - Determinação da resistência à tração na flexão de corpos de prova prismáticos. Rio de Janeiro, 2010.

ASSOCIAÇÃO BRASILEIRA DE NORMAS. ABNT NBR 15530 (2007): Fibras de aço para concreto - Especificações. Rio de Janeiro, 2007.

ACI - AMERICAN CONCRETE INSTITUTE. Manual of concrete practice: Guide for specifying, proportioning, mixing, placing, and finishing steel fiber reinforced concrete (ACl 544.3R-93). ACl Committee 544, Detroit, USA, 1993.

BARR, B. et al. Toughness measurement - the need to 
think again. Cement and Concrete Composites, v. 18, p. 281-297, 1996.

BENTUR, A.; MINDESS, S. Fibre reinforced cementitious composites. United Kingdom. Barking, Elsevier. 1990.

BOULEKBACHE B., HAMRAT M., MOHAMED C., AMZIANE $S$. Flexural behaviour of steel fibre-reinforced concrete under cyclic loading. Construction and Building Materials, v 126, p. 253-262, 2016.

CHEN, L.; MINDESS, S.; MORGAN, D. R. Specimen geometry and toughness of steelfiber-reinforced concrete. 1994. Journal of Materials in Civil Engineering, v. 6, n. 4, p. 529-541, nov. 1994.

FIGUEIREDO, A. D. Concreto com Fibras de Aço. 2000. Escola Politécnica da Universidade de São Paulo. Boletim Técnico. São Paulo, 2000.

FIGUEIREDO, A. D. Concreto reforçado com Fibras. 2011. Escola Politécnica da Universidade de São Paulo. Tese (Livre-Docência). Departamento de Engenharia de Construção Civil. São Paulo, 2011.

GAMINO, A. L. Análise numérica da ductilidade de vigas de concreto armado convencional e de alto desempenho. 2003. Dissertação (Mestrado) - Faculdade de Engenharia de Ilha Solteira, Universidade Estadual Paulista. Ilha Solteira, 2003.

GARCEZ, E. A. Análise teórico-experimental do comportamento de concretos reforçados com fibras de aço submetidos a cargas de impacto. 2005. Dissertação (Mestrado em Estruturas) - Programa de Pós-Graduação em Engenharia Civil, PPGEC, UFRGS, Porto Alegre, 2005.

GAVA, G. P. Análise teórica-experimental do comportamento à flexão de vigas de concreto reforçado com fibras de aço. 2006. Tese (Doutorado em Engenharia Civil) - Programa de Pós-Graduação em Engenharia Civil, Universidade Federal de Santa Catarina. Florianópolis, 2006.

GHASEMI M., GHASEMI M. R., MOUSAVI S. R. Investigating the effects of maximum aggregate size on self-compacting steel fiber reinforced concrete fracture parameters. Construction and Building Materials, v. 162, p. $674-682,2018$.

GOPALARATNAM, V.; GETTU, R. On the caracterization of flexural toughness in fiber reinforced concretes. 1995. Cement \& Concrete Composites, v. 17, p.239-254, 1995.

HAITANG Z., SHENGZHAO C., DANYING G., SHEIKH M. N., CHUANCHUAN L. Flexural behavior of partially fiberreinforced high-strength concrete beams reinforced with FRP bars. Construction and Building Materials, v. 161, p. 587-597, 2018.

JAMET, D. et. al. Toughness of fiber-reinforced highstrength concrete from notched beam tests. In: Testing of Fibre Reinforced Concrete - American Concrete
Institute Spring Convention, SP 155, 1995, Salt Lake City - Utah. Proceedings. p. 23-39. Utah: ACl, 1995.

Karihaloo B. L., Vriese K. M. B. de. Short-fibre reinforced reactive powder concrete. in H.W. Reinhardt and A.E. Naaman (eds) High Performance Fiber Reinforced Cement Composites (HPFRCC 3), RILEM Proceedings PRO 6, RILEM Publications, Bagneux, 1999, pp. 53-63.

Kang S. T., Kim J. K., Investigation on the flexural behavior of UHPCC considering the effect of fiber orientation distribution. Construction and Building Materials. v. 28, p. 57-65, 2012.

LOPES, M. M. Substituição parcial de armadura de flexão por fibras de aço em vigas de concreto. 2005. Tese (Mestrado em Engenharia Civil) - Universidade Federal do Rio de Janeiro. Rio de Janeiro, 2005.

MEHTA, P. K.; MONTEIRO, P. J. M. Concreto: estrutura, propriedades e materiais. São Paulo: Pini, 1994.

MEHTA, P. K.; MONTEIRO, P. J. M. Concreto: microestrutura, propriedades e materiais. São Paulo: IBRACON, 2008.

NAAMAN, A. E. Fiber reinforcements for concrete: looking back, looking ahead. In: Fibrereinforcedconcretes (FRC) .2000. Proceedings. Edited by P. Rossi and G. Chanvillard. p. 65-85. Lyon, France, 2000

NUNES, L. N.; AGOPYAN, V. A Influencia do Fator de Forma da Fibra na Tenacidade à Flexão do Concreto Reforçado com Fibras de Aço. Escola Politécnica da Universidade de São Paulo. Boletim Técnico. São Paulo, 1998.

OM Construtora. Blog OM Construtora: Fibras de Aço. $2000 . \quad$ Disponível em: <http://omconstrutora.blogspot.com.br/>. Acesso em: 11 nov. 2016, 19:51:53.

RILEM TC 162-TDF: Test and design methods for steel fibre reinforced concrete - Recommendation. Materials and Structures/Materiaux et Constructions, v. 33, p. 3-5, mar. 2000.

ROBINS, P. et al. Flexural strain and crack width measurement of steel-fibre reinforced concrete by optical grid and electrical gauge methods. 2001. Cement and Concrete Research, v. 31, p. 719-729, 2001.

RODRIGUES, E. Dosagem do concreto. Notas de Aula. Instituto de Tecnologia, Universidade Federal Rural do Rio de Janeiro. Seropédica, 2003.

RUANO G., ISLA F., PEDRAZA R. I., SFER D., LUCCIONI B Shear retrofitting of reinforced concrete beams with steel fiber reinforced concrete. Construction and Building Materials, v. 54, p. 646-658, 2014.

Sun W., Liu S., Lai J. Study on the properties and 
mechanism of ultra-high performance ecological reactive powder concrete. A.E. Naaman and H.W. Reinhardt (eds) High Performance Fiber Reinforced Cement Composites, RILEM Proceedings PRO 30, RILEM Publications, Bagneux, 2003, pp. 409-417.

TAYLOR, M.; LYDON, F. D.; BARR, I. G. Toughness measurements on steel fibrereinforced high strength concrete. Cement and Concrete Composites, v. 19, p. 329340, 1997. 